\title{
STRATEGI PEMBELAJARAN AGAMA ISLAM PADA SITUASI PANDEMI BAGI ANAK SEKOLAH DASAR MELALUI METODE IDO DASA CITA
}

\author{
Hilma Gusparima, Adi Junaidi², Kharisma Nur Pratama3, Refianto Damai \\ Darmawan4, Lindawati Kartika5 \\ 1,2,3,4,5,Institut Pertanian Bogor \\ ${ }^{1}$ E-mail address hilma gusparima@apps.ipb.ac.id; 2 E-mail address \\ Adidijun@apps.ipb.ac.id; 3E-mail address kharisma pratama@apps.ipb.ac.id; 4E-mail \\ address $\underline{\text { rdamaid@gmail.com; 5E-mail address Lindawati.kartika@gmail.com }}$
}

\begin{abstract}
Juvenile delinquency is a phenomenon caused by many causes, and one of them is the lack of religion comprehension and its application in daily life. One way to instill a good religion comprehension in childhood is through an active learning approach, where students learn and play, and in this case using IDO Box: Islamic Dolanan. Active learning method is quite complex so that an effective approach and appropriate environment is needed, especially in a pandemic condition. The aim of this research are to know the appropriate media in implementing IDO Box and increasing the student's religion comprehension. This research was done in Taman Pendidikan Al Quran (TPA) Anugrah, Bojongsari, Depok City, West Java. Learning media that was used in this research are learning modules, website, learning videos, and webinars that were done online. Primary data was obtained by online interviews and questionnaires. IDO Box was implemented using The House Model that was created by Horovitz and Ohlsson-Corboz (2007). The House Model concept is divided into three parts that is vision mission purpose (roof), program indicators and milestones (middle), and IDO Box program and media (cornerstone). Overall the IDObox program consisted of 10 main indicators that has been completed 100\% through the activities, i.e. Quran memorizing test, Islamic stories, online assignments, online quizzes, webinars, and also parents and teachers satisfaction survey. This accomplishment is supported by pretest, posttest, and learning improvement evaluation in terms of cognitive, affective, psychomotor, and learning outcomes.
\end{abstract}

Keywords: Bojongsari Depok, IDO Dasa Cita, IDO Box

\begin{abstract}
Abstrak
Kenakalan remaja merupakan fenomena yang disebabkan oleh banyak hal, dan salah satunya adalah kurangnya pemahaman agama serta pengamalannya dalam kehidupan. Salah satu cara menanamkan pemahaman agama yang baik pada masa kecil adalah dengan pendekatan active learning, di mana siswa-siswi belajar sambil bermain. Perlu diadakan pendekatan yang tepat dan lingkungan yang sesuai ditengah
\end{abstract}


pandemi ini, salah satunya menggunakan pendekatan bermain dan belajar bersama IDO BOX : Islamic Dolanan. Tujuan dari penelitian ini adalah mengetahui media yang paling baik dalam mengimplementasikan IDO Box serta meningkatkan pemahaman agama Islam pada siswa. Penelitian ini dilakukan di Taman Pendidikan Al Quran (TPA) Anugrah, Bojongsari, Depok, Jawa Barat. Media pembelajaran yang digunakan adalah dengan buku modul pembelajaran, laman web, video pembelajaran, dan webinar yang dalam pelaksanaannya dilakukan secara daring. Data primer diperoleh dengan wawancara secara daring dan kuisioner. Metode pengimplementasian IDO Box menggunakan The House Model yang diusung oleh Horovitz dan Ohlsson-Corboz (2007). Konsep the House Model dibagi menjadi tiga bagian yakni visi misi dan tujuan (atap), indikator dan capaian program (tengah) serta program dan media IDO Box (fondasi). Secara keseluruhan program IDO Box terdiri dari 10 indikator utama yang telah mencapai target $100 \%$ melalui kegiatan setoran hafalan Quran, dongeng islami, penugasan secara daring, kuis daring, webinar serta kepuasan orangtua dan guru. Keberhasilan tersebut didukung dengan pretest dan post test serta evaluasi peningkatan pembelajaran dari segi kognitif, afektif, psikomotorik, maupun luaran pembelajaran.

Kata Kunci: Bojongsari Depok, IDO Dasa Cita, IDO Box

\section{PENDAHULUAN}

Globalisasi telah memasuki era yang bernama revolusi industri 4.0. Revolusi industri 4.0 secara fundamental mengakibatkan berubahnya cara manusia berpikir, hidup, dan berhubungan satu dengan yang lain. Dampak positif dengan adanya revolusi industri 4.0 adalah digitalisasi disektor kehidupan serta terciptanya efisiensi dan efektifitas diberbagai kegiatan. Namun, revolusi industri 4.0 menyimpan berbagai dampak negatif diantaranya dengan hilangnya nilai-nilai sosial humaniora seperti gaya hidup konsumerisme, kebebasan yang tanpa batas, serta hilangnya prilaku etis di media sosial (Prasetyo \& Trisyanti, 2018).
Menurut Badan Pusat Statistik Nasional (2019) bahwa jumlah kejahatan (crime total) dan risiko penduduk terkena kejahatan (crime rate) yang terjadi di Indonesia, Provinsi Jawa Barat masuk ke dalam peringkat ke-5 Kepolisian Daerah (Polda) dengan jumlah kasus sebanyak 16.209. Salah satu kota yang masuk ke dalam daerah Provinsi Jawa Barat adalah wilayah Kota Depok. Kepolisian Resor (Polres) Metro Depok mengemukakan 30\% yang terlibat tindak kriminalitas di Depok adalah remaja. Beberapa tindak kriminalitas yang dilakukan oleh remaja di Depok seperti pencurian, pembegalan maupun pengedaran narkoba (Iswinarno, 2019). Fase remaja merupakan masa peralihan manusia dari 
anak-anak menuju dewasa yang merupakan tahap dalam pencarian jati diri. Jika tidak ada bimbingan dan perhatian yang serius dari orang tua maka akan berdampak kepada permasalahan yang mucul di kalangan remaja seperti tindak kriminalitas (Wakhidah, 2016).

Maraknya kriminalitas remaja yang terjadi di masyarakat, mengharuskan semua pihak seperti pemerintah, instansi pendidikan, dan masyarakat turut berperan dalam mengatasi masalah tersebut dan mencari solusi terbaik yang dapat dilakukan. Dengan Indonesia merupakan Negara Pancasila, dimana sila pertama dalam Pancasila berbunyi Ketuhanan Yang Maha Esa dan didukung dengan mayoritas masyarakat Indonesia yang beragama Islam termasuk di Kota Depok. Oleh karena itu, alternatif yang dapat dilakukan adalah melalui pendidikan agama Islam. Pendidikan agama Islam diharapkan mampu menghasilkan manusia yang selalu berupaya menyempurnakan iman, takwa, dan berakhlak mulia. Akhlak mulia mencakup etika, budi pekerti atau moral sebagai perwujudan dari pendidikan (Ainiyah, 2013). Karakter seperti itu yang diharapkan dapat membentuk seseorang yang tangguh dalam menghadapi tantangan, hambatan, dan perubahan yang muncul dalam pergaulan bermasyarakat baik dalam lingkup lokal, regional, nasional, maupun global.

TPA Anugrah yang ada di Kelurahan Curug, Kecamatan Bojongsari, Kota Depok, merupakan salah satu sarana Pendidikan Agama Islam yang tersedia secara gratis di tengah-tengah pemukiman masyarakat yang ada di Kecamatan Bojongsari, Kota Depok. TPA Anugrah dalam menjalankan kegiatan pembelajarannya baru sebatas mengajarkan Al Quran secara umum, belum menambahnya dengan pembelajaran mengenai ilmu tajwid, ibadah, akidah, akhlak, dan sejarah islam serta implementasi pembelajaran yang nantinya dapat menanamkan budaya baik sejak dini pada anak-anak. Ditambah dengan kemampuan sumber daya pengajar yang terbatas dan belum terintegrasinya sistem pembelajaran yang ada, membuat anak-anak mudah bosan dan tidak optimal dalam melakukan proses pembelajaran yang dijalankan. Dengan merebaknya pandemi Covid-19, mengharuskan kegiatan belajar mengajar dilakukan secara daring (dalam jaringan). Maka dari itu, adanya salah satu inovasi mahasiswa yang mendukung kegiatan belajar di rumah yang menyenangkan untuk anak dalam belajar mengenai Ilmu Agama dan menghafal Al 
Quran yaitu dengan IDO (Islamic Dolanan) Box.

IDO Box mempunyai prinsip bermain sekaligus belajar serta menghafal Al Quran. Prinsip bermain dan belajar dibentuk karena kebutuhan anak akan bermain dengan memberikan pembelajaran dan nilai-nilai Islami yang dibutuhkan oleh anak. Permainan IDO Box hadir untuk membantu memperbaiki akhlak generasi muda dengan kecintaannya terhadap Al Quran sehingga menciptakan peradaban unggul generasi rabani. IDO Box merupakan sebuah permainan untuk mengedukasi anak terkait Ilmu Agama seperti ilmu tajwid, aqidah, akhlak, ibadah, sejarah Islam, sekaligus metode menghafal $\mathrm{Al}$ Quran yang menyenangkan dengan didukung kurikulum yang terintegrasi. Metode yang digunakan dalam permainan IDO Box yaitu Active Learning melalui konsep IDO Dasa Cita. Metode Active Learning diterapkan untuk menjaga perhatian anak didik agar tetap tertuju pada proses pembelajaran. Sehingga memungkinkan anak untuk berperan aktif dalam proses pembelajaran dalam bentuk interaksi maupun dalam proses pembelajaran tersebut.

Luaran kegiatan yang diharapkan dari pelaksanaan Program IDO Box adalah dengan terciptanya panduan IDO
Box berupa modul (buku panduan, buku tugas, buku mutabaah, buku panduan orangtua) dan kurikulum pembelajaran (aqidah, akhlak, ibadah, ilmu tajwid, sejarah Islam) bagi anak melalui bimbingan orangtua dan guru. Kemudian dapat terbentuknya platform pembelajaran daring berbasis web dan media sosial seperti yang berkaitan terkait materi pembelajaran, dongeng Islami menggunakan boneka Salmah dan Salman, webinar parenting, Parentstory Podcast dan Mom Review. Serta dapat terciptanya permainan Do It Yourself (DIY) Engklek Hafidz IDO Box, terbentuknya komunitas atau agent of change generasi cinta $\mathrm{Al}$ Quran (Fundraiser, Relawan) dan Jurnal pengabdian masyarakat.

\section{METODE DAN PELAKSANAAN \\ Metode}

Metode yang digunakan untuk analisis program IDO Box adalah metode The House Model (Horovitz and Ohlsson, 2007) dan Net Promotor Score (Monkey Survey, 2017). Penyusunan metode melalui beberapa langkah yaitu: (1) cascading visi, misi, dan sasaran pada unit kerja terkait, (2) membuat kartu skor yang sesuai dengan kaidah SMART, (3) tentukan indikator kinerja utama (IKU), (4) perhitungan range skala sangat baik, baik, cukup, dan kurang 
untuk setiap IKU, (5) perhitungan bobot tiap IKU, (6) perhitungan capaian yang telah direalisasikan.

Program IDO Box dilaksanakan dengan metode IDO Dasa Cita Model untuk menjawab persoalan tersebut. IDO Dasa Cita memiliki makna sepuluh citacita IDO Box yang harus dicapai untuk menciptakan peradaban unggul generasi rabani.

\section{Pelaksanaan Kegiatan}

Program IDO Box dilaksanakan pada tanggal 10 Agustus hingga 30 September 2020 secara daring bersama mitra yaitu TPA (Taman Pendidikan Al Quran) Anugrah yang berlokasi di Curug, Bojongsari-Depok. Program IDO Box telah terlaksana berupa kegiatan setoran hafalan (Quran dan materi) daring, cerdas cermat (lomba daring dan kuis), dongeng Islami, webinar parenting, parentstory podcast dan mom review, review guru, dan Do It Yourself (DIY) Engklek Hafidz IDO Box. Sumber data primer diperoleh dari wawancara secara daring sedangkan data sekunder diperoleh dari data statistik Kecamatan Bojongsari, data statistik nasional, dan jurnal terkait. Pengolahan data pre-test dan post-test dilakukan dengan menghitung rata-rata aspek kognitif, afektif dan psikomotorik, dan learning outcome. Hasil rata-rata tersebut disajikan dalam bentuk grafik dengan membandingkan perbedaan nilai pretest dan post-test pada ketiga aspek. Kemudian untuk tahap pelaksanaan program terdiri dari persiapan, implementasi, dan monitoring dan evaluasi program yang dilakukan secara daring.

\section{HASIL DAN PEMBAHASAN}

Pembelajaran IDO Box mengadopsi Teori Pembelajaran Bloom (1956) yang memiliki tiga (3) sasaran kinerja yaitu kognitif, afektif dan psikomotorik dengan sepuluh (10) indikator utama berupa (1) Aspek kognitif meliputi memahami rukun Islam dan Iman, hafalan Asmaul Husna dan sifat wajib Allah, hafalan Al Quran, hafalan doa-doa harian. (2) Aspek afektif dan psikomotorik meliputi adab dalam berilmu, kisah Nabi dan Rasul, praktik wudhu dan sholat, membaca Al Quran sesuai dengan hukum tajwid melalui buku panduan IDO BOX seperti Guide Book, Parents Guide, Buku Mutabaah, Buku Tugas, Brosur cara bermain IDO. (3) Aspek learning outcomes meliputi kepuasan dan guru terhadap program IDO melalui testimoni (in Depth Interview online) dan video testimoni mengenai EPBM IDO.

Berdasarkan

identifikasi permasalahan, terdapat empat permasalahan utama yaitu minimnya 
guru ngaji, mutu pendidikan yang masih rendah, krisis moral dan kepribadian, kondisi ekonomi dan keluarga maka dibentuklah Program IDO Box dengan metode IDO Dasa Cita untuk menjawab persoalan tersebut. Pada Gambar 1. Dapat diketahui bahwa implementasi program IDO Box terdiri atas tiga bagian, yakni atap yang merupakan visi, misi, dan tujuan utama IDO, bagian tengah tediri dari indikator dan capaian program serta bagian dasar yang

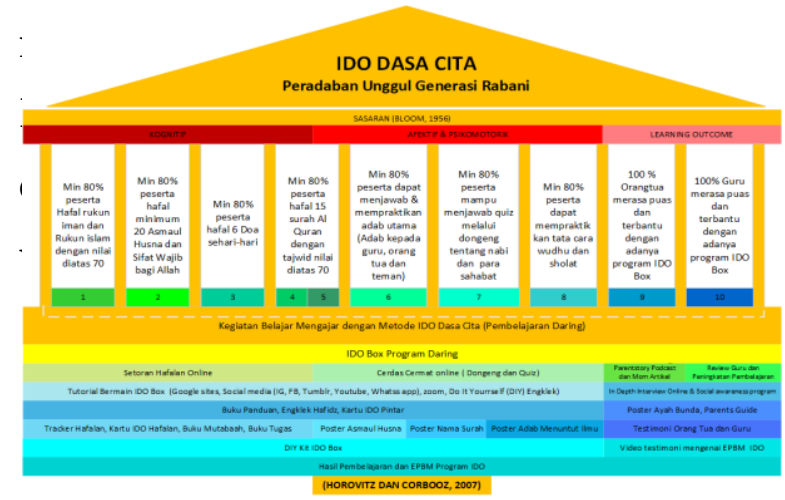

Gambar 1. IDO Dasa Cita Model

\section{Hasil Evaluasi Kognitif: Dasa Cita Pertama}

Indikator pembelajaran kognitif IDO Dasa Cita Pertama yaitu menghafal dan memahami Rukun Islam dan Rukun Iman melalui kegiatan setoran hafalan secara daring.

Tabel 1. Hasil Evaluasi Dasa Cita I

\begin{tabular}{|l|c|c|c|}
\hline \multicolumn{1}{|c|}{$\begin{array}{c}\text { Indikator } \\
\text { Kinerja }\end{array}$} & $\begin{array}{l}\text { Pre- } \\
\text { Test }\end{array}$ & Target & $\begin{array}{l}\text { Post } \\
\text { Test }\end{array}$ \\
\hline $\begin{array}{l}\text { Minimal 80\% } \\
\text { peserta hafal } \\
\text { rukun islam dan } \\
\text { rukun iman } \\
\text { dengan nilai } \\
\text { diatas 70. }\end{array}$ & $41 \%$ & $80 \%$ & $89 \%$ \\
\hline
\end{tabular}

Hasil pengukuran yang telah dilakukan, peserta telah mencapai target yakni sebesar $89 \%$ yang dapat dilihat pada Tabel 1. Hal tersebut menunjukkan peserta telah mampu menghafal dan memahami rukun Islam dan iman yang merupakan pilar penting sebagai pedoman hidup umat Muslim.

\section{Hasil Evaluasi Kognitif: Dasa Cita Kedua}

Pembelajaran Asmaul Husna dan sifat wajib bagi Allah SWT dilakukan secara daring. Materi disampaikan melalui media pembelajaran IDO Box di media sosial. Mempelajari Asmaul Husna dan sifat wajib bagi Allah SWT merupakan amalan yang paling utama (dasar keimanan) sehingga harapannya dapat meningkatkan keimanan peserta.

Tabel 2. Hasil Evaluasi Dasa Cita II

\begin{tabular}{|c|c|c|c|}
\hline $\begin{array}{c}\text { Indikator } \\
\text { Kinerja }\end{array}$ & $\begin{array}{l}\text { Pre- } \\
\text { Test }\end{array}$ & Target & $\begin{array}{l}\text { Post } \\
\text { Test }\end{array}$ \\
\hline $\begin{array}{l}\text { Minimal 80\% } \\
\text { peserta hafal } 20 \\
\text { Asmaul Husna } \\
\text { dan sifat wajib } \\
\text { bagi Allah. }\end{array}$ & $37 \%$ & $80 \%$ & $89 \%$ \\
\hline
\end{tabular}

diketahui bahwa target pembelajaran Asmaul Husna dan sifat wajib bagi Allah SWT tercapai sebesar 89\%. Penilaian melalui kegiatan kuis dan setoran secara daring. 
Hasil Evaluasi Kognitif: Dasa Cita Ketiga

Kegiatan menghafalkan doa seharihari dapat mengasah perkembangan anak pada aspek kognitif, bahasa maupun moral dan agama. Melalui kegiatan berdoa peserta dapat memperkuat kesehatan mental, baik untuk penyembuhan, pencegahan maupun untuk pembinaan.

Tabel 3. Hasil Evaluasi Dasa Cita III

\begin{tabular}{|c|c|c|c|}
\hline $\begin{array}{c}\text { Indikator } \\
\text { Kinerja }\end{array}$ & $\begin{array}{c}\text { Pre- } \\
\text { Test }\end{array}$ & Target & $\begin{array}{c}\text { Post } \\
\text { Test }\end{array}$ \\
\hline $\begin{array}{c}\text { Minimal 80\% } \\
\text { peserta hafal 6 } \\
\text { doa sehari-hari. }\end{array}$ & $72 \%$ & $80 \%$ & $85 \%$ \\
\hline
\end{tabular}

Kegiatan pembelajaran dasa cita

ketiga dapat dilihat pada Tabel 3. Peserta telah mampu menghafal enam doa sehari-hari melalui kegiatan kuis dan setoran doa secara daring. Kegiatan menghafal dilakukan secara berkala dan terjadwal sehingga anak dapat menghafal secara bertahap.

\section{Hasil Evaluasi Kognitif: Dasa Cita Keempat \& Kelima}

Sebagai seorang Muslim wajib hukumnya untuk membaca, mempelajari dan mengamalkan Al Quran. Karena AlQuran memiliki kedudukan yang tinggi dan merupakan wahyu dari Allah SWT. Maka dari itu, pada kegiatan pembelajaran dasa cita keempat dan kelima yaitu hafalan Al Quran dan materi tajwid penting dilakukan.
Tabel 4. Hasil Evaluasi Dasa Cita IV \& V

\begin{tabular}{|l|c|c|c|}
\hline \multicolumn{1}{|c|}{$\begin{array}{c}\text { Indikator } \\
\text { Kinerja }\end{array}$} & $\begin{array}{c}\text { Pre- } \\
\text { Test }\end{array}$ & Target & $\begin{array}{c}\text { Post } \\
\text { Test }\end{array}$ \\
\hline $\begin{array}{l}\text { Minimal 80\% } \\
\text { peserta hafal 11 } \\
\text { surah Al Quran } \\
\text { dengan nilai } \\
\text { diatas 70 }\end{array}$ & $27 \%$ & $80 \%$ & $93 \%$ \\
\hline
\end{tabular}

Berdasarkan Tabel 4. Bahwa

capaian hafalan Quran dan tajwid peserta mencapai target yaitu sebesar 93\% yang hafal 11 surah dengan mengimplementasikan tajwid yang telah dipelajari. Kegiatan pembelajaran daring berupa setoran hafalan Quran, kuis, DIY Kit IDO Box. Harapannya dengan menghafal Quran peserta mampu memahami kandungan surah yang dihafal dan dapat menambah kebijaksanaan, keimanan serta mengimplementasikannya dalam kehidupannya.

\section{Hasil Evaluasi Afektif dan}

\section{Psikomotorik: Dasa Cita Keenam}

Pentingnya beradab sebelum berilmu menunjukkan bahwa adab merupakam hal utama yang harus dipelajari. Sebab beberapa ulama menganjurkan untuk lebih lama mempelajari adab sebelum mempelajari ilmu agar dapat memaknai ilmu yang dipelajarinya. Pada pembelajaran IDO Dasa Cita yang keenam, peserta mempelajari terkait adab-adab dalam berilmu, adab kepada orangtua, guru, maupun ke teman sebaya. 
Tabel 5. Hasil Evaluasi Dasa Cita VI

\begin{tabular}{|l|c|c|c|}
\hline $\begin{array}{c}\text { Indikator } \\
\text { Kinerja }\end{array}$ & $\begin{array}{c}\text { Pre- } \\
\text { Test }\end{array}$ & Target & $\begin{array}{c}\text { Post } \\
\text { Test }\end{array}$ \\
\hline $\begin{array}{l}\text { Minimal 80\% } \\
\text { peserta dapat } \\
\text { menjawab dan } \\
\text { memperaktikan } \\
\text { adab-adab utama. }\end{array}$ & $63 \%$ & $80 \%$ & $89 \%$ \\
\hline
\end{tabular}

Penyampaian materi adab pada program IDO melalui kegiatan dongeng secara daring dengan menggunakan media zoom meeting dan youtube, materi di media sosial, quiz dan tugas. Sehingga anak dapat memahami materi yang disampaikan seperti yang digambarkan pada Tabel 5 .

\section{Hasil Evaluasi Afektif dan Psikomotorik: Dasa Cita Ketujuh}

Mempelajari sejarah Islam penting dilakukan, peserta dapat memahami (ketentuan-ketentuan Allah) dalam sejarah, mencontoh teladan yang baik, serta dapat mengambil banyak pelajaran. Materi IDO Dasa Cita Ketujuh terkait sejarah nabi dan rasul serta para sahabat nabi yang dapat menjadi teladan bagi anak.

Tabel 6. Hasil Evaluasi Dasa Cita VII

\begin{tabular}{|l|c|c|c|}
\hline \multicolumn{1}{|c|}{$\begin{array}{c}\text { Indikator } \\
\text { Kinerja }\end{array}$} & $\begin{array}{l}\text { Pre- } \\
\text { Test }\end{array}$ & Target & $\begin{array}{l}\text { Post } \\
\text { Test }\end{array}$ \\
\hline $\begin{array}{l}\text { Minimal 80\% } \\
\text { peserta mampu } \\
\text { menjawab kius } \\
\text { melalui dongeng } \\
\text { tentang nabi dan } \\
\text { para sahabat. }\end{array}$ & $37 \%$ & $80 \%$ & $93 \%$ \\
\hline
\end{tabular}

Berdasarkan Tabel 6. Peserta telah mampu menjawab kuis terkait sejarah Islam. Kegiatan pembelajaran dilakukan secara daring melalui kegiatan dongeng dan kuis di media sosial.

\section{Hasil Evaluasi Afektif dan Psikomotorik: Dasa Cita Kedelapan}

Shalat merupakan salah satu sarana yang paling utama dalam hubungan antara manusia dengan Tuhan serta mempunyai kedudukan yang sangat penting dan mendasar dalam Islam. Pada pembelajaran IDO Dasa Cita Kedelapan, peserta menghafal bacaan sholat serta mempraktikkannya.

Tabel 7. Hasil Evaluasi Dasa Cita VIII

\begin{tabular}{|l|c|c|c|}
\hline $\begin{array}{c}\text { Indikator } \\
\text { Kinerja }\end{array}$ & $\begin{array}{c}\text { Pre- } \\
\text { Test }\end{array}$ & Target & $\begin{array}{c}\text { Post } \\
\text { Test }\end{array}$ \\
\hline $\begin{array}{l}\text { Minimal 80\% } \\
\text { peserta dapat } \\
\text { mempraktikan tata } \\
\text { cara wudhu dan } \\
\text { shalat. }\end{array}$ & $56 \%$ & $80 \%$ & $85 \%$ \\
\hline
\end{tabular}

Evaluasi Dasa Cita Kedelapan yaitu praktik wudhu dan sholat mencapai hasil sesuai target. Peserta dapat mempraktikkan tatacara sholat dengan baik dapat dilihat pada Tabel 7. Melalui pembalajaran ini, harapannya peserta dapat menjalankan sholat 5 waktu sesuai dengan aturan dan ajaran Islam.

\section{Hasil Evaluasi Learning Outcomes: \\ Dasa Cita Kesembilan \& Kesepuluh}

Evaluasi Dasa Cita Kesembilan dan Kesepuluh menggunakan penilaian Net Promotor Score (NPS) yaitu nilai kepuasan mitra dan kemungkinan untuk merekomendasikan layanan/kegiatan kepada teman atau kolega dengan nilai 9 
atau 10 "promotor", nilai 7 atau 8 "pasif" dan nilai dibawah 6 "detractor".

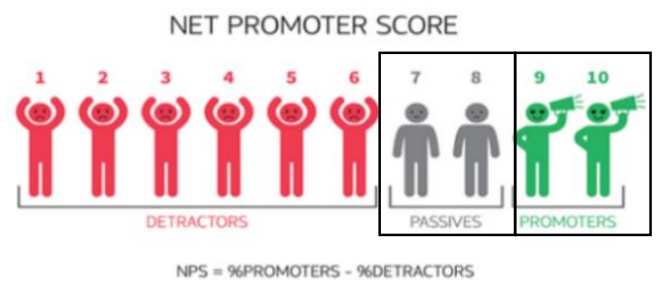

Gambar 2. Net Promotor Score Orangtua dan Guru

Program IDO Box memiliki nilai net promoter score orangtua sebesar 86\% dengan promoter sebesar 86\%, passive $14 \%$ dan detractor sebesar o\% yang dapat dilihat pada Gambar 2. Sehingga dapat dibuktikan bahwa orangtua $100 \%$ puas dengan program yang diikuti. Begitu juga nilai net promoter score guru yaitu $100 \%$ merasa puas dan terbantu dengan adanya program IDO Box dan merekomendasikan program kepada orang lain.

\section{Hasil Evaluasi Publikasi \& Kerjasama IDO Box}

Kegiatan IDO Box perlu dipublikasikan untuk menginspirasi masyarakat luar tergerak melaksanakan program yang sejenis. IDO Box sedang dalam proses melakukan berbagai publikasi melalui media cetak, elektronik, dan jurnal. Selain itu, kegiatan IDO Box tentunya tidak dapat berjalan dengan lancar tanpa bantuan dan kerjasama dengan berbagai pihak.

Tabel 8. Hasil Evaluasi Kerjasama

\begin{tabular}{|c|c|c|c|}
\hline $\begin{array}{c}\text { Indikator } \\
\text { Kinerja }\end{array}$ & $\begin{array}{c}\text { Real } \\
\text { isasi }\end{array}$ & Target & $\begin{array}{c}\text { Penca } \\
\text { paian }\end{array}$ \\
\hline $\begin{array}{c}\text { Kerjasama } \\
\text { yang telah } \\
\text { terlaksana }\end{array}$ & 5 & 3 & $100 \%$ \\
\hline \multicolumn{3}{|c|}{ Berdasarkan Tabel 8} & dapat \\
\hline
\end{tabular}

diketahui indikator publikasi yang telah dilakukan dan kerjasama terjalin dengan pihak eksternal telah melampaui target yang telah ditetapkan. Keberlanjutan Program akan berjalan lancar atas dukungan dan kerjasama dengan berbagai pihak. Sejauh ini sudah ada 5 kerjasama yang terjalin antara IDO Box dengan berbagai pihak. Adapun jenis kerjasama yang terjalin yaitu dengan Birena Al Hurriyyah, Lembaga Pengajar Quran Al Hurriyyah, Rumah Lusyan Bogor, TPA Sahabat Quran Depok, TPA Al Qohar Depok dan SALAM UI. Berdasarkan hasil evaluasi, dapat diketahui seluruh indikator telah melampaui target yang ditetapkan sehingga capaian program secara keseluruhan adalah $100 \%$.

\section{Faktor Pendorong dan Penghambat Program}

Berdasarkan hasil evaluasi program, dapat dirumuskan beberapa faktor pendorong berdasarkan hasil wawancara secara daring bersama guru di TPA Anugrah Bojongsari, Depok (Suminah, 2020) yaitu; wawancara dengan kepala sekolah, dan beberapa guru terdapat jawaban yang sama antara 
lain; (a) Manajemen perencanaan yang sesuai dengan visi dan misi TPA, (b) Kekompakan dari seluruh warga TPA untuk mewujudkan tempat pembelajaran Quran yang berasaskan kekeluargaan dengan tanpa dipungut biaya dalam proses pembelajaran, (c) Minat belajar yang tinggi dari siswa-siswi. (d) Dukungan dari masyarakat, (e) Rasa tanggung jawab dari semua tim untuk selalu komitmen dalam menjalankan tugas.

Berdasarkan hasil wawancara tersebut dapat dipahami bahwa faktor pertama yang menjadi faktor pendorong terwujudnya program IDO Box di tempat mitra adalah dengan perencanaan yang matang semua aspek. Rencana dilaksanakan dengan kompak dan komitmen. Pelaksanaan yang dilengkapi dengan sarana yang memadai akan memudahkan semua program yang dijalanlan. Disamping sarana dan prasarana dukungan dari berbagai pihak (masyarakat maupun pemerintah) sangat menentukan keberlanjutan program yang dijalankan. Kemudian melakukan evaluasi terkait hasil yang dicapai, tingkatkan mutu program serta perbaiki kelemahankelemahan yang dijumpai.

Mewujudkan rencana dalam satu pekerjaan selalu ada kendala yang ditemui. Demikian juga dengan mewujudkan program edukasi berbasis agama Islam dan kecintaan pada $\mathrm{Al}$ Quran yang diusung oleh Tim IDO Box di daerah Bojongsari, Depok. Menurut Suminah selaku Kepala Sekolah TPA Anugrah dan beberapa guru terdapat beberapa kendala dalam mewujudkan TPA yang lebih terorganisir dan interaktif, antara lain; (a) Rendahnya tingkat ekonomi masyarakat sekitar, (b) Kurangnya kesadaran masyarakat terkait ilmu agama Islam, (c) Kondisi lingkungan yang kurang mendukung (d) Minimnya sarana dan prasarana yang memadai, (e) Minimnya sumber daya pengajar, (f) Belum tersedianya kurikulum dan materi ajar yang terintegrasi.

\section{Keberlanjutan Program}

Program dan permainan IDO Box telah diadopsi sebagai kurikulum pembelajaran dasar-dasar Islam dan metode menghafal Quran oleh TPA Anugrah dengan dukungan orangtua peserta serta didampingi oleh Birena Al Hurriyyah.

Dalam bidang pendidikan, program ini memberikan peran yang besar untuk kemajuan pendidikan khususnya anakanak di TPA Anugrah. Dari hasil yang dicapai, permainan DIY Kit IDO Box mampu mejadi metode hafalan Quran yang menyenangkan bagi peserta. Permainan dan Program IDO Box 
memiliki potensi untuk dikembangkan melalui kerjasama dengan pihak-pihak lembaga pendidikan untuk sarana penunjang proses belajar-mengajar setelah mendapatkan hak paten.

Kami telah bekerjasama dengan Birena Al Hurriyyah untuk mereplikasi program IDO Box di daerah lain dan jangkauan yang lebih luas. Hal tersebut didukung oleh kerjasama dengan TPA dan Komunitas Pendidikan di DepokBogor. Buku Panduan "Generasi Rabani bersama IDO Box" yang dapat dijadikan pedoman oleh pihak TPA/sekolah/komunitas pendidikan yang akan mereplikasi program IDO Box ke seluruh daerah Depok dan Bogor khususnya serta Indonesia pada umumnya.

\section{PENUTUP}

\section{Simpulan}

IDO Box merupakan solusi model pembelajaran bagi anak sekolah dasar dalam meningkatkan pendidikan agama Islam serta hafalan Al Quran. Permainan DIY Kit IDO Box merupakan inovasi dari englek, bersifat aplikatif sehingga menciptakan kegiatan kerohanian yang menyenangkan dan dapat dilakukan di rumah bersama keluarga. IDO Box berhasil meningkatkan capaian pembelajaran di TPA Anugrah sampai 88\% dengan kegiatan secara daring sudah terlaksana 100\%, yakni pada mata ajar rukun Islam dan Rukun Iman, hafalan Asmaul Husna dan sifat wajib Allah, hafalan surah Al Quran, hafalan doa-doa harian, praktik sholat, materi adab dan sejarah Islam. IDO Box memiliki peluang perluasan dan keberlanjutan yang potensial melalui kerjasama dengan berbagai pihak baik akademisi (pakar pendidikan agama Islam dan parenting), bisnis (Program CSR), pemerintah (Dinas Pendidikan) dan komunitas/relawan.

\section{Saran}

Pengembangan IDO Box perlu dilakukan dengan keterlibatan sinergi antara pemerintah, swasta, pengusaha, organisasi dan masyarakat baik secara lokal, regional, maupun nasional sehingga dapat menciptakan pembelajaran Islam dan metode hafalan Al Quran yang tepat bagi anak-anak mitra. IDO Box dapat direplikasi di wilayah-wilayah lain di Indonesia untuk meningkatkan motivasi anak dalam menghafal Al Quran serta mempelajari ilmu agama Islam sehingga menciptakan peradaban unggul generasi rabani.

\section{Ucapan Terima Kasih}

Rasa terima kasih kami sampaikan kepada Kementerian Riset, Teknologi, dan Pendidikan Tinggi yang telah membiayai perintisan program IDO Box 
melalui Program Kreativitas Mahasiswa bidang Pengabdian Masyarakat (PKMM) tahun 2020 dan para donatur yang telah berpartisipasi dalam menyukseskan program ini.

\section{DAFTAR PUSTAKA}

Affan, H., 2020. Komunitas LGBT 'Melawan' Pernyataan Wali Kota Depok: 'Ini Rumah Kami, Saya Harus Bertahan', Depok: Radar Depok.

Ainiyah, N., 2013. Pembentukan Karakter Melalui Pendidikan Agama Islam. Jurnal Al-Ulum, 1(13), pp. 26-27.

Arifianto, B., 2018. Pemetaan Mutu

Pendidikan, Banyak Sekolah di

Depok Belum Kumpulkan Data,

Depok: Pikiran Rakyat.

Bloom, B. S., 1956. Taxonomy of Educational Objectives. In: Handbook I Cognitive Domain. New York: Longmans, Greeen and Co.

Horovitz, J. \& Corboz, A. O., 2007. A Dream with a Deadline: Turning Strategy into Action. Harlow [GB]: FT Prentice Hall.

Iswinarno, C., 2019. Selama 2019, Pelaku Kriminal di Kota Depok Didominasi Remaja Tanggung, Depok: Suarajabar.id.
Ma'arif, S., 1991. Pendidikan Islam di Indonesia Antara Cita dan Fakta. Yogyakarta: Tiara Wacana.

Monkey, S., 2017. Mengenal Net Promotor Score. [Online] Available at:https://www.surveymonkey.com /mp/mengenal-net-promoterscore/

Prasetyo, B. \& Trisyanti, U., 2018. Revolusi Industri 4.0 dan Tantangan Perubahan Sosial. IPTEK Journal of Proceedings Series, Volume 5, pp. 22-27.

Statistik, B. P., 2019. Jumlah Penduduk per-Kelurahan se-Kecamatan Bojongsari. [Online] Available at: https://bojongsari.depok.go.id/prof il/kependudukan [Accessed 20 Oktober 20].

Statistik, B. P., 2019. Statistik Kriminal. [Online] Available at: https://www.bps.go.id/publication /2019/12/12/66co114edb7517a33o 63871f/statistik-kriminal2019.html [Accessed 20 Oktober 2020].

Suminah, 2020. Rata-rata Tingkat Pendidikan Kampung Curug [Interview] (Kamis Agustus 2020).

Wakhidah, M. N., 2016. Bimbingan dan Konseling Pada Remaja ala Islami, Jakarta: Kompasiana. 